\title{
Trends in the Addition of PET and Natural Fibers to the Concrete- Steel Reinforcement System
}

\author{
Sánchez-Torres $\mathrm{R}^{1}$, Onofre-Bustamante $\mathrm{E}^{1 *}$, Espindola Flores $\mathrm{AC}^{1}$, Morales-Cepeda $\mathrm{AB}^{2}$ and Rodríguez-Gómez \\ $\mathrm{FJ}^{3}$
}

${ }^{1}$ Instituto Politécnico Nacional, CICATA Unidad Altamira, Mexico

${ }^{2}$ Tecnológico Nacional de México/Instituto Tecnológico de Ciudad Madero, Mexico

${ }^{3}$ Departamento de Ingeniería Metalúrgica, Universidad Nacional Autónoma de México, Ciudad Universitaria, Mexico

Submission: November 13, 2021; Published: November 29, 2021

*Corresponding author: Onofre Bustamante E, Instituto Politécnico Nacional, CICATA Unidad Altamira, Km 14.5 Carretera Tampico-Puerto Industrial Altamira, 89600 Altamira, Mexico

\begin{abstract}
Due to the nature of the aggregates used in the manufacture of concrete and therefore of the concrete- steel reinforcement system, as well as its growing demand, a negative environmental impact has been caused on the planet. Therefore, at present green alternatives are sought that can reduce the negative impact of the construction industry particularly concrete, some of these alternatives with greater positive impact are: the addition of natural fibers of vegetable origin and the addition of polymers such as recycled Polyethylene Terephthalate (PET), because both materials abound on the planet, they are easy to obtain, and positively impact the environment by reusing them, reducing the use of raw material and energy invested in the elaboration of concrete, which in turn cause the increase in Greenhouse Gases (GHG). Therefore, from this work of review of the state of the art and published trends involving the use of PET and natural fibers in concrete, the effect that the addition of these fibers has on the properties of the concrete-reinforcing steel system, and its impact on the construction industry, was determined. The effect on mechanical properties was mainly reviewed, however, recent studies show that electrochemical properties such as the susceptibility to corrosion of the reinforcing steel embedded in the concrete are also affected, because the presence of oxides on the reinforcing steel causes cracking, weakening the structures, causing a sudden failure of them. However, it is known that this corrosion process mainly affects structures exposed to saline environments such as bridge piles immersed in the sea. Therefore, the study of the concrete-reinforcing steel system and its modification through the addition of natural fibers or polymers partially replacing natural aggregates such as gravel and sand remains of the utmost importance, in order to reduce on the one hand, the environmental impact caused by the exploitation of the natural mantles from which the aggregates are obtained and on the other hand increase the life time of the concrete-reinforcing steel system. This approach is promising especially if one takes into account the results in the literature, which positively point to the addition of PET and natural fibers, since it has been determined that they increase some mechanical and electrochemical properties depending on the form and quantity in which it is incorporated into the concrete mixture.
\end{abstract}

Keywords: Concrete; Polyethylene terephthalate (PET); Natural fibers; Mechanical properties; Electrochemical properties

\section{Introduction}

Currently the construction industry consumes large amounts of raw material and energy, contributing greatly to environmental (atmospheric) pollution, mainly favoring the release of greenhouse gases (GEI) [1]. Furthermore, it is known that the corrosion of reinforcing steel embedded in concrete is one of the main causes of its deterioration, it is also an electrochemical process and for many years efforts and arduous studies have been directed in search of improving the electrochemical and mechanical properties of the concrete-reinforcing steel system. Mainly because these properties are important for their performance and durability, that is, it seeks to increase the useful life of constructions such as: buildings, bridges and houses. In recent years the use of natural fibers in the elaboration of the concentrate has been greatly increased, plants such as Diss [2], hemp [3] have been studied to mention an example. The use of plants of plant origin is based on the ease of access and availability of them as well as the environmental and economic impact of their reuse. However, a good adhesion between the fibers and the concrete is required to improve its mechanical properties, that is, a fibrous plant is required to promote this property. Moreover, another promising alternative is the recycling of polymeric compounds 


\section{Civil Engineering Research Journal}

such as PET [4]. Mainly because the use of PET for reuse would generate a decrease in the constant growth of plastic waste (low biodegradability) that is produced in the world. Today more than 13 million tons of plastic go into the oceans, it is estimated as a consequence, that every year more than 100,000 marine mammals die [5].

In the construction industry, concrete occupies more than $85 \%$ [6] of the materials used in large constructions and mechanical properties are critical to determining the effectiveness of concrete. Therefore, recent studies on concrete have focused on modifications through different aggregates such as natural fibers seeking mainly to improve their performance in terms of mechanical and electrochemical properties by manufacturing new ecological concretes [3,7]. In 2018, the effect on concrete was studied when hemp fiber is added in different proportions $0.5,1,2$ and $3 \%$ and lengths of 6,12 and $18 \mathrm{~mm}$. Subsequently, tests of resistance to compression, bending and tensile breaking were carried out. The results showed that specimens at 2 and $3 \%$ hemp, $12 \mathrm{~mm}$ in length, presented an increase in their mechanical strength with respect to the reference. The results were as follows: reference specimen, compressive strength of $31.14 \mathrm{MPa}$, bending strength $5.02 \mathrm{MPa}$, tensile breaking resistance of $2.08 \mathrm{MPa}$, while specimens with $2 \%, 3 \%$ hemp with $12 \mathrm{~mm}$ length reported compressive strengths of $34.28 \mathrm{MPa}, 34.67 \mathrm{MPa}$, at flexion of $5.47 \mathrm{MPa}, 5.82 \mathrm{MPa}$ and tensile breakage of $3.71 \mathrm{MPa}$ and 4.10 MPa. This represents a $10-15 \%$ increase in mechanical properties directly related to the presence of natural fiber (hemp) of $2 \%, 3 \%$ replacing the fine aggregate in concrete. Additionally, it has been reported [3], that the size of the natural fibers that are poured into the mixture plays an important role in the performance of the concrete modified with natural fibers. Fibers smaller than $20 \mathrm{~mm}$ in length were reported to have a higher compressive strength than the reference sample, Additionally [8] in 2019 the $0.8 \%$ cane bagasse fiber was proposed to partially replace the fine aggregate, obtaining compressive strengths around $30 \mathrm{MPa}$, in accordance with the ASTM C39/C39M-17 standard [9]. In 2013, the benefits of working with natural fibers were reported by extracting residual sugars and waterproofing them in order to reduce water absorption, characteristic of natural fibers in order not to affect the water/cement ratio of concrete [2], obtaining favorable preliminary results. The results of many investigations show the possibility of using different plants with similar characteristics to extract their fibers and add them to the concrete to improve or match their mechanical properties mainly. However, other alternatives have been exploited such as the recycling of polyethylene terephthalate (PET) in concrete, in which, it has been reported that its main effect is reflected in the increase in mechanical properties such as compressive strength, tensile strength by division, static elastic modulus and flexural strength, among others. In 2013, cylindrical concrete specimens were manufactured by adding PET in the form of fibers with dimensions of 6 to $10 \mathrm{~mm}$ in length and replacing $0.5,1$ and $1.5 \%$ of the fraction volume. The results obtained corresponding to the specimen with the volume of $0.5 \%$ PET presented a considerable increase in mechanical properties with respect to the reference.

However, they reported that adding a higher percentage of PET (1 and 1.5\%) causes a decrease in mechanical properties, the workability of the concrete mixture and an increase in porosity [10]. Subsequently, it was proposed to add PET fibers with lengths greater than those previously reported, showing an increase in the maximum bending load [11]. In 2017, the reduction in the workability of the mixture was corroborated by adding PET in fibers with lengths greater than $0.5 \%$ by volume [12]. In 2019, through dynamic tensile tests and weight drop tests in particular with the presence of PET fibers, the increase in tensile strength properties and elastic modulus was reported. However, I decrease the toughness and fault stress with the increase in the deformation rate [13]. In the same sense, the decrease in workability and compressive strength has been reported, attributing it to the existence of a vacuum around the fibers [14]. In 2020, the response was compared in terms of mechanical properties, modifying the concrete using $100 \%$ recycled PET, $100 \%$ virgin PET and polyethylene (PE), the material with the best results was using 100\% recycled PET [15]. Additionally, in 2019 a steel bar was designed with powdered PET, which increased the tensile and compressive strength of the rods by $17.2 \%$ and $19.3 \%$ respectively and was attributed to powdered PET proving to be an additive material of good resistance [16]. Likewise, the electrochemical properties such as the susceptibility to corrosion of the reinforcing steel embedded in the concrete are also affected, as a consequence of the presence of oxides on the reinforcing steel, which causes cracking, weakening the structures. In this sense, in 2020 conventional electrochemical tests were carried out to determine the effect of PET on the anticorrosive properties of concrete, PET was added in different geometries in proportions of 3,5 and $8 \%$ to the fine aggregate (sand) and reported a considerable decrease in the corrosion rate, demonstrating that the addition of PET provides some protection to the reinforcing steel embedded in the concrete [7].

\section{Conclusion}

It has been shown in different works that modifying the chemical composition of concrete using natural fibers or recycled PET increases the mechanical and electrochemical properties depending on the size, geometry, and the way in which they are added to the concrete mixture. Fibers of lengths greater than $18 \mathrm{~mm}$ and in greater percentage, reduce the workability of the mixture, as well as the mechanical properties, mainly due to the size and quantity of the fibers in the mixture prevent the integration of the fibers homogeneously in the concrete paste, causing agglomerates that function as defects that favor the growth and nucleation of cracks. However, the subject is not exhausted and motivates the realization of research works that deepen the effect of the modification of concrete by adding 


\section{Civil Engineering Research Journal}

natural fibers and or recycling polymers in different particle sizes and geometry, performing a chemical, structural, mechanical and electrochemical characterization that allow laying the foundations considering even the alkali-hydrolysis reactions and their effect on the aforementioned properties, to reproduce in the construction industry while reducing pollution of municipal solid waste and greenhouse gases caused by the high consumption of raw materials and energy. Therefore, a research work is proposed which consists of the manufacture of a concrete with the addition of recycled PET with a granulometry that replaces the fine aggregate (sand), in percentages in volume of 5, 10 and $25 \%$, as well as designing a mixture that includes water lily (LA) fibers as a substitute for sand, in percentages in relation to its volume of 1 , 2.5 and $5 \%$ as a reinforcing material and one more mixture that includes the combination of PET/LA in percentages of 5/1,10/2.5 and $25 / 5 \% \mathrm{v}$, in search of a homogeneous mixture that increases the mechanical and electrochemical properties of the concrete reinforcing steel system.

\section{References}

1. Egelston A (2013) Sustainable Development A History. Springer, New York, USA.

2. Sellami A, Merzoud M, Amziane S (2013) Improvement of mechanical properties of green concrete by treatment of the vegetals fibers. Construction and building materials 47: 1117-1124.

3. Comak B, Bideci A, Salli O (2018) Effects of hemp fibers on characteristics of cement-based mortar. Construction and building materials 169: 794-799.

4. Merli R, Preziosi M, Acampora A, Lucchetti M, Petrucci E (2020) Recycled Fibers in Reinforced Concrete: a systematic literature review. Elservier 248: 119-207.

5. Rivera O, Álvarez L, Rivas M, Garelli O, Pérez E, et al. (2020) Impact of plastic pollution in Mexican protected natural areas. Green Peace, Mexico.
6. Mobasher B (2008) USA-concrete construction industry-cement based materials and civil infrastructure. CBM-CI International Workshop Karachi Pakistan 73-90.

7. Díaz Y, Menchaca E, Rocabruno C, Uruchurtu J (2020) Effect of Recycled PET (Polyethylene Terephthalate) on the Electrochemical Properties of Rebar in Concrete. International Journal of Civil Engineering 18: 487-500.

8. Islam M, Ahmed S (2018) Influence of jute fiber on concrete properties. Construction and Building Materials 189: 768-776.

9. Huertas L, Martinez P, Espitia M (2019) Analysis of the compressive strength property of concrete modified with sugarcane bagasse fibers (Saccharum officinarum). International Congress of Innovation and Trends in Engineering (CONIITI).

10. Irwan J, Asyraf R, Othman N, Koh H, Annas M (2013) The Mechanical Properties of PET Fiber Reinforced Concrete From Recycled Bottle Wastes. Advanced Materials Research 795: 347-351.

11. Baldenebro F, Castorena J, Velazquez J, Ledezma J, Gómez C, et al. (2014) Influence of continuous plastic fibers reinforcement arrangement in concrete strengthened. IOSR Journal of Engineering 4(4): 15-23.

12. Dinesh Y, Hanumantha C (2017) Strength characteristics of Fiber Reinforced Concrete using Recycled PET. International Journal of Civil Engineering and Technology (IJCIET) 8(4): 92-99.

13. Lei Y, Wei Z, Ozbakkalogl T, Guo J, Feng J, Bo J (2019) Dynamic Behavior of PET FRP and Its Preliminary Application in Impact Strengthening of Concrete Columns. Applied Sciences 9: 49-87.

14. Khatab H, Mohammed S, Hameed L (2019) Mechanical Properties of Concrete Contain Waste Fibers of Plastic Straps. IOP Conference Series: Materials Science and Engineering 557: 15-16.

15. Signorini C, Volpini V (2021) Mechanical Performance of Fiber Reinforced Cement Composites Including Fully Recycled Plastic Fibers. Fibers 9: 16.

16. Jawadab F, Adarshaa C, Raghavendra T, Udayashankara B, Natarajanc K (2019) Structural behavior of concrete beams and columns reinforced with Waste Plastic incorporated GFRP (WPGFRP) rebars. Journal of Building Engineering 23: 172-184.

\section{Your next submission with Juniper Publishers will reach you the below assets}

- Quality Editorial service

- Swift Peer Review

- Reprints availability

- E-prints Service

- Manuscript Podcast for convenient understanding

- Global attainment for your research

- Manuscript accessibility in different formats

(Pdf, E-pub, Full Text, Audio)

- Unceasing customer service

Track the below URL for one-step submission https://juniperpublishers.com/online-submission.php 